\title{
Flexural Behavior of CFRP Laminate at Elevated Temperature
}

\author{
Rzgar M. Abdalrahman \\ Production Engineering and Metallurgy \\ Sulaimani Polytechnic University \\ Sulaimani, Iraq \\ rzgar.abdalrahman@spu.edu.iq
}

\begin{abstract}
A carbon fibre reinforced polymer (CFRP) laminate forms the surface part of an integrally heated tool. It was made up of carbon non-crimp triaxial fibre and SR8100 epoxy in accordance to the stacking sequence of $[(0, \pm 45) /(90, \pm 45)] s$, using the resin infusion (RI) method. The laminate is heated up to $90^{\circ} \mathrm{C}$ when the tool is operated; therefore understanding the effect of temperature on the flexural properties is quite significant. This experimental study is carried out to investigate the flexural behaviour of the CFRP laminate and finding its flexural properties under the effect of elevated temperatures. For this purpose, various CFRP specim-ens were prepared and tested, using three point bending test method, at different temperature levels from room temperature to $90^{\circ} \mathrm{C}$. The results show that each of the flexural peak load, modulus and strength of the laminate decreases consistently with the increase of temperature. Also the laminate becomes slightly more flexible and significant loss occurs in its flexural modulus when the temperature elevates from $75^{\circ} \mathrm{C}$ to $90^{\circ} \mathrm{C}$. The reduction in the flexural behaviour of CFRP is imputed to thermal softening of the epoxy polymer matrix whenever becomes closer to (HDT).
\end{abstract}

KEYWORDS : CFRP laminate, flexural modulus, high temperature and flexural test.

\section{INTRODUCTION}

Nowadays, application of carbon fibre reinforced polymer (CFRP) composites have become quite popular in aerospace, automotive, defence, marine, sporting goods and infrastructure industries, because CFRP compared to aerospace aluminium and steel alloys can provide lower density and expansivity (low CTE) as well higher specific modulus (modulus/density) and higher specific strength (strength/density) and chemical inertness [1]. The CFRP structure is polymer matrix composites (PMC) reinforced by carbon fibre. The premixed advanced compound of CFRP, known as prepreg, is be produced by retaining the polymer matrix in CFRP combination in a partially cured condition over prolonged period of time [2]. Both the fibre and reinforcement components are insoluble in each other and they are differing in their physical form and chemical composition.

Properties of the fibre content are generally dominant in composites and improve their mechanical properties such as strength and stiffness. However the matrix stiffness and its mechanical strength are lower than those of reinforcement, it acts as binder, holds the fibre together, transfers mechanical loads through the fibres to the rest of the structure and protects fibres from mechanical (impact, abrasion and corrosion) and environmental actions [3, 4]. One of the important characteristic specific to solid materials is flexural modulus, therefore many researchers have determined this characteristic, using the three point bending test, to understand the effect different factors on the adaptable mechanical properties of composites [5]. CFRP composite can provide well-bonded structures with excellent strength and hardness after curing, but the viscoelastic properties of polymers causes the main problem of polymeric materials that results in creep and a high sensitivity to temperature [6].

The test material, in this study, is a CFRP laminate used in building an integrally heated tool. The laminate structure is an epoxy system of SR8100 reinforced by non-crimp fabric (NCF) triaxial carbon and it is exposed to heat up to $90^{\circ} \mathrm{C}$ when the tool is been used. Therefore, the current study aims to investigate the flexural behaviour of the CFRP laminate at elevated temperature and base on this a number of CFRP specimens are tested to failure, using three points bending, at different levels of temperature between room temperature and $90^{\circ} \mathrm{C}$. Results presented that the increase of temperature reduces the flexural properties consistently and drastic decrease is observed in the flexural modulus after increasing the test temperature from $75^{\circ} \mathrm{C}$ to $90^{\circ} \mathrm{C}$ that a reaches the heat distortion temperature (HDT).

\section{LITERATURE REVIEW}

Many studies have been conducted to define effects of different factors on the bending stiffness of different anisotropic composite plates, using a three-point support bending test. They deduced that the composite properties are tailorable and they are not only functions of the constituents but they are also affected by many other factors, such as; the nature of matrix and reinforcement, fibre volume fraction, the compatibility between the components, materials processing technology and conditions, the dispersion or distribution of the filler in the matrix, working environment (temperatures, humidity. etc.), the interfacial structure and morphology, fibre orientation, laminate stacking, surface waviness and moulding temperature [5, 7-10]. For instance; Azzam A. \& Li W. [5] deduced that quasi-isotropic types of stacking sequences of composite laminate structure exhibits a brittle behaviour, while the unbalance type exhibits a progressive failure mode consisting of fibre failure.

Considerable amount of research were conducted recently to investigate the effect of different environment 
factors, such as; humidity, vibration and especially temperature on various CFRP structures [11]. Most of the researches have been carried out on fibre reinforced polymers (FRPs) that are used in construction, strengthening and repairing of reinforced concrete structures [12-14], for example; Gamage et al. [15] concluded that that epoxy loses its strength rapidly at the temperature around $73^{\circ} \mathrm{C}$. Also, Reis, J. M. L. [16] studied the effect of a range of temperatures varying from room temperature to $90^{\circ} \mathrm{C}$ on the performance of epoxy and polyester polymer mortars (mixture of foundry sand with the thermoset resin binder) and they concluded that both the flexural and compressive strength are changing inversely with the increase of temperature and the epoxy polymer mortars are more sensitive to temperature variation.

During testing several concrete specimens externally bonded with CFRP, Di Tommaso et al. [17] obtained that the failure load at $40^{\circ} \mathrm{C}$ lower than that at room temperature, while Klamer et al. [18], found contradictory results because the failure load increased at $40^{\circ} \mathrm{C}$ and $50^{\circ} \mathrm{C}$ and suddenly decreased above a threshold temperature of $65^{\circ} \mathrm{C}$. That behaviour was due to the fact that the epoxies will undergo a transition from a hard rigid state to a more pliable (rubbery state) when it reaches the glass transition temperature $(\mathrm{Tg})$, (midpoint of a transition temperature range) that depends on the resin or the polymer type [19]. Aforementioned review illustrates that the mechanical properties of polymers change considerably at high temperature, especially when it reaches its HDT.

\section{EXPERIMENTAL WORK}

\section{Material:}

The material is a CFRP laminate of $3.1 \mathrm{~mm}$ thick and 0.53 fibre volume fraction $\left(V_{f}\right)$, which forms the surface part of an integrally heated tool. The laminate is prepared according to the stacking sequence of $[(0, \pm 45) /$ $(90, \pm 45)]_{\mathrm{s}}$, using resin infusion under flexible tooling (RIFT) processing method. Four layers of non-crimp fabric (NCF) triaxial carbon of $660 \mathrm{~g} / \mathrm{m}^{2}$ areal-weight from Sigmatex Industries [20], are applied as the reinforcement, each layer consists three lamina of parallel fibres laid in three different orientations of $(0, \pm$ 45) Figurer 1.

Table 1: properties of the SR 8100 Epoxy (at $20^{\circ} \mathrm{C}$ ) [21]

\begin{tabular}{lc}
\multicolumn{1}{c}{ Properties } & Value \\
\hline Viscosity $(\mathrm{m} . P a s)$ & $930 \pm 100$ \\
Density $\left(\mathrm{g} / \mathrm{cm}^{3}\right)$ & 1.158 \\
$\mathrm{Tg}\left({ }^{\circ} \mathrm{C}\right)$ & $74-81$ \\
$\mathrm{HDT}\left({ }^{\circ} \mathrm{C}\right)$ & 85 \\
Tensile strength $(\mathrm{MPa})$ & 60 \\
Tension modulus of elasticity $(\mathrm{MPa})$ & 2700 \\
Flexion modulus of elasticity $(\mathrm{MPa})$ & 2850 \\
Elongation at break $(\%)$ & 12
\end{tabular}

The matrix is the two components, injection and infusion, epoxy system SR8100 with SD8824 standard hardener from Sicomin Composites [21]. The resin properties at room temperature provided by the manufacturer illustrated in Table 1 . The combination was allowed to cure for 3 days at room temperature and then the laminate is post-cured in an oven for 16 hours at $80^{\circ} \mathrm{C}$ with a ramp rate of $3^{\circ} \mathrm{C} / \mathrm{min}$. The laminate is considered as the most appropriate material due to its good structural performance at room temperature, but there is lack of information about its flexural behaviour, when the tool works and temperature rises to $90^{\circ} \mathrm{C}$.

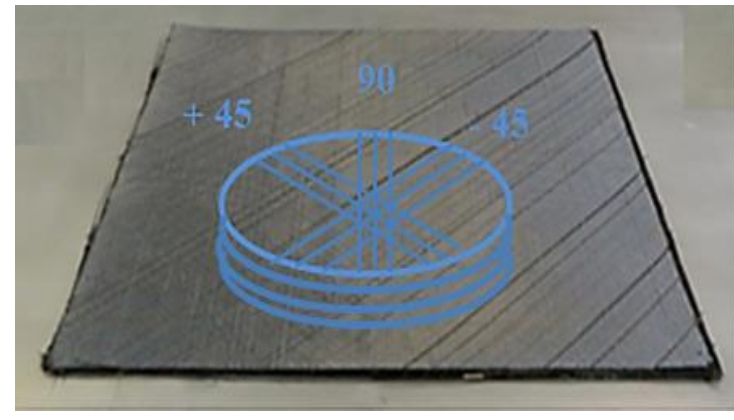

Figure 1: The CF layers before processing according to stacking sequence of $[(0, \pm 45) /(90, \pm 45)] \mathrm{s}$.

\section{Test procedure:}

Different uniform rectangular specimens, Figure 2, are cut from the produced CFRP laminate with the dimensions illustrated in Table 2 and at a span to depth ratio of 32, in accordance with ISO 14125 [22].

Table 2 : The main dimensions of the test specimen according to ISO 14125 [22]

\begin{tabular}{cc} 
Dimensions & Value $(\mathbf{m m})$ \\
\hline Depth $(\mathrm{h})$ & 3.13 \\
Width $(\mathrm{d})$ & 14.8 \\
Span length (Ls) & 120 \\
Total length (L) & 150
\end{tabular}

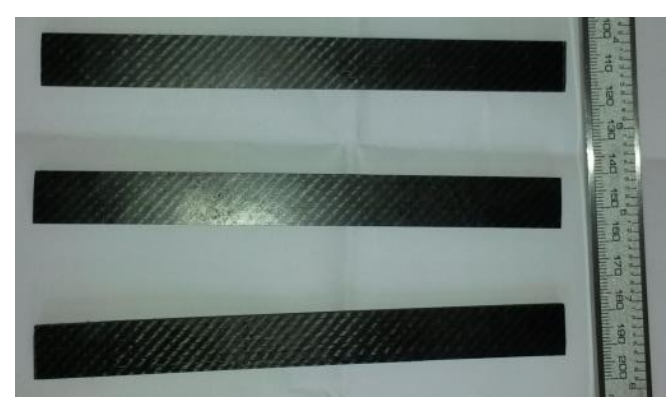

Figure 2 : CFRP specimens prepared for flexural test.

A number of flexural tests are carried out for the specimens at $22^{\circ} \mathrm{C}, 35^{\circ} \mathrm{C}, 50^{\circ} \mathrm{C}, 65^{\circ} \mathrm{C}, 75^{\circ} \mathrm{C}$ and $90^{\circ} \mathrm{C}$ on an Instron 3367 machine (Figure 3 ) at a loading speed of $0.03 \mathrm{~mm} / \mathrm{sec}$ using the three-point bending method in accordance with ASTM D790-07 [23]. Each test is repeated three times to verify results. Prior to each bending test, the specimen is exposed to heat inside a temperature controlled oven to reach the desired test temperature. Then the heated specimen is wrapped by insulator during transferring to the test jig to prevent heat loss. 


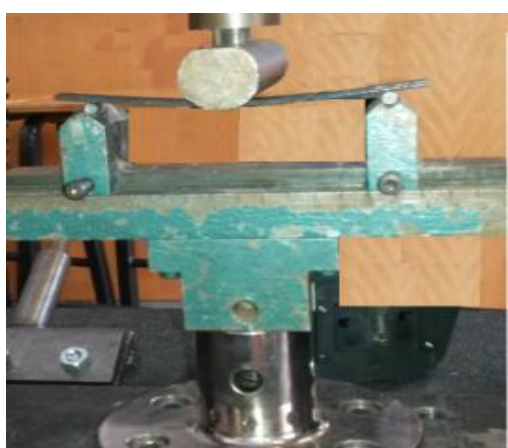

Figure 3 : Three-point bending test on the Instron 3367 machine.

\section{RESULTS AND DISCUSSION}

This research work was achieved with the aim of understanding the flexural behavior of CFRP laminate and finding its flexural properties under the effect of different levels of temperature from room temperature to $90^{\circ} \mathrm{C}$. Different rectangular CFRP specimens, according to standards, were prepared for this purpose, using cutting saw and grinder equipment.

The bending test results of the CFRP specimens, at each particular temperature level, are illustrated as loaddeflection curves in Figure 4. The figure shows that with the increase of temperature the CFRP material loses $60 \%$ of peak load (flexural load resistance) at a rate of about 4 $\mathrm{N} /{ }^{\circ} \mathrm{C}$ from $500 \mathrm{~N}$ to $198 \mathrm{~N}$. Also it shows that the flexural behaviours of elastic deformation and sudden drop of the load for all the CFRP specimens tested at the temperatures range from room temperature to $75^{\circ} \mathrm{C}$. The initial part of each load-deflection curve that has a linear appearance exhibits the bending stiffness to peak load and elastic deformation of the specimen because no delamination and oscillations were observed before the peak load.

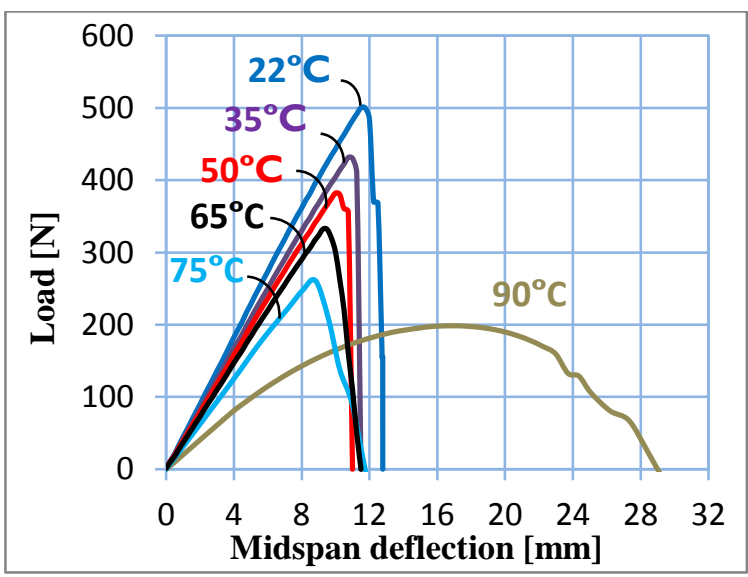

Figure 4 : Load-displacement curves of the CFRP specimens at different test temperatures

The sudden drop of the load, after reaching the peak value, represents brittle behaviour of the laminate due fibre cracking as it was noticed during the tests and presented in Figure 5a. After the load drop, it was observed that the specimens continued to afford flexural load but never exceeded previous peak load because only the reinforcement resisted. Compared with the load- displacement curves for the specimens tested at temperatures below $90^{\circ} \mathrm{C}$, obvious difference can be noticed in the curve shape of that tested at $90^{\circ} \mathrm{C}$, also the tested specimen, as shown in Figure 5b, was the only that formed around the test machine indenter without fracture. This difference in behaviour indicates a sudden change in the property of the specimen material that becomes pliable and less brittle because its temperature has reached the HDT of the epoxy component, Table 1, which relates closely to the resin glass transition temperature and corresponds to the initial softening point.

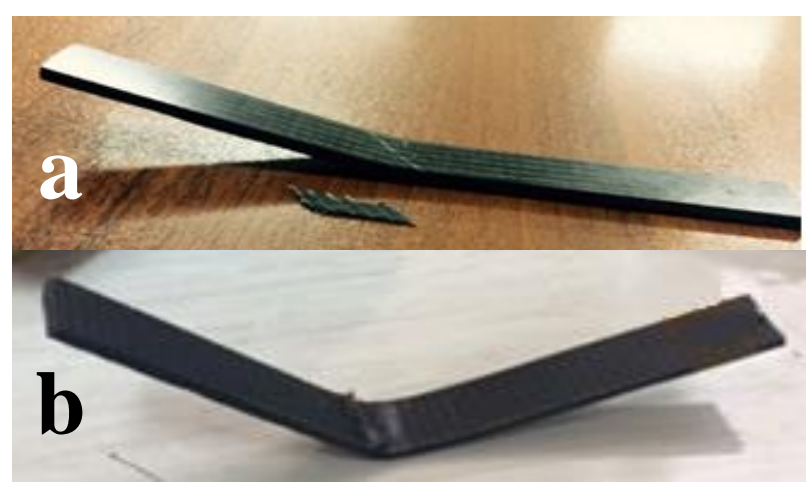

Figure 5: Failure of the CFRP specimens in flexural test (a) at $35^{\circ} \mathrm{C}(\mathrm{b})$ at $90^{\circ} \mathrm{C}$

The flexural modulus $\left(E_{f l}\right)$ and flexural strength $\left(\sigma_{f l}\right)$ of each test specimen at each specified temperature level are calculated from the specimen dimensions (Table 2), the slop $(m)$ and the peak load $\left(F_{P}\right)$ values of the correlated load-displacement curve, as shown in Figure 4 , according to the following equations [22].

$$
\begin{gathered}
\sigma_{f l}=\frac{3 F_{p} L}{2 b h^{2}} \\
E_{f l}=\frac{m L^{3}}{2 b h^{2}}
\end{gathered}
$$

The obtained values are plotted in Figure 6 versus the test temperatures range from room temperature to $90^{\circ} \mathrm{C}$. Accordingly a consistent decrease of $60.4 \%$, over the entire increasing of test temperatures, can be observed in the flexural strength of the CFRP laminate at a rate of $10^{-2} \mathrm{GPa} /{ }^{\circ} \mathrm{C}$ from $0.61 \mathrm{GPa}$ to $0.24 \mathrm{GPa}$. Furthermore, between the room temperature and $75{ }^{\circ} \mathrm{C}$, the laminate loses $29 \%$ of its flexural modulus gradually from 45 $\mathrm{GPa}$ to $31.8 \mathrm{GPa}$ at a rate of $0.2 \mathrm{GPa} /{ }^{\circ} \mathrm{C}$, but significant decrease of $40 \%$ occurs from $32 \mathrm{GPa}$ to $14 \mathrm{GPa}$ at a rate of $1.2 \mathrm{GPa} /{ }^{\circ} \mathrm{C}$ when the temperature elevates from $75^{\circ} \mathrm{C}$ to $90^{\circ} \mathrm{C}$.

Thus it could be deduced that the effect of temperature is quite significant, despite the flexural properties being dominated by the fibres at the outer surfaces, because the laminate loses properties constantly whenever the specimen temperature becomes closer to the HDT of the epoxy component. This will be important to select proper epoxy with suitable HDT for designing the CFRP laminates that are working at elevated temperatures and providing high thermal degradation resistance.

On the other hand, however, temperature elevation 


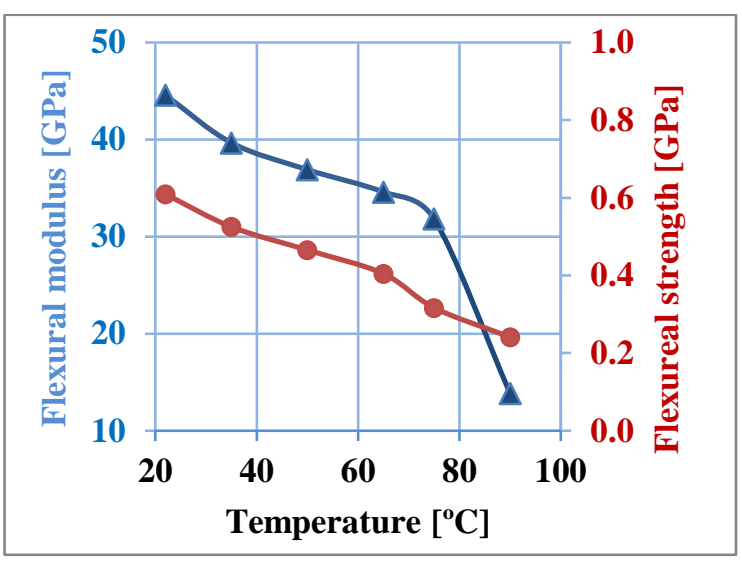

Figure 6 : Flexural modulus and ultimate stress of the CFRP specimens as function of temperature.

decreases the laminate properties of flexural strength and modulus; it softens the laminate and makes it slightly more pliable that can improve some features like impact and vibration resistance as well as slightly higher peel strength. This flexible feature is also useful for the CFRP laminates that are bonded to dissimilar materials with different coefficients of thermal expansion (CTE) as occurred in the integrally heated tool and increases the delamination resistance of the tool.

\section{CONCLUSION}

In this study, the flexural test results of the CFRP laminate specimens at different levels of temperature up to $90^{\circ} \mathrm{C}$ show that:

1. The temperature dependency of the CFRP laminate properties related strongly to the resin HDT. This will be important in selecting proper epoxy with suitable HDT during designing the CFRP laminates that are working at elevated temperatures to achieve high thermal degradation resistance.

2. The CFRP laminate retains its behaviours of elastic deformation, sudden load drop and brittle fracture At the temperature levels from room temperature to $75^{\circ} \mathrm{C}$.

3. After load drop, the laminate continues in resisting the flexural load till final failure but never exceeds the previous peak load because only the fibre resists.

4. The CFRP laminate loses consistently $60 \%$ of peak load (from $500 \mathrm{~N}$ to $198 \mathrm{~N}$ ) and flexural strength (from $0.61 \mathrm{GPa}$ to $0.24 \mathrm{GPa}$ ) at rates of about 4 $\mathrm{N} /{ }^{\circ} \mathrm{C}$ and $10^{-2} \mathrm{~N} /{ }^{\circ} \mathrm{C}$, respectively, over the entire test temperatures from room temperature to $90^{\circ} \mathrm{C}$.

5. The CFRP laminate loses $29 \%$ of its flexural modulus from $45 \mathrm{GPa}$ to $32 \mathrm{GPa}$, at a rate of 0.2 $\mathrm{GPa} /{ }^{\circ} \mathrm{C}$, gradually due to the temperature change from the room temperature to $75^{\circ} \mathrm{C}$ but the losing increases drastically to $40 \%$ (from $32 \mathrm{GPa}$ to 14 $\mathrm{GPa})$ and the rate to $1.2 \mathrm{GPa}$ when the temperature elevated from $75^{\circ} \mathrm{C}$ to $90^{\circ} \mathrm{C}$.
6. The CFRP laminate becomes slightly more flexible with the increase of temperature and more when it reaches HDT.

\section{REFERENCES}

[1] Q. Shen, M. Omar, and S. Dongri, "Ultrasonic NDE techniques for impact damage inspection on CFRP laminates," Journal of materials science research, 1(1), pp. 34-36, 2012.

[2] G. P. Thomas, "Composite Prepregs Manufacturing, Benefits and Applications," 2013. [Online]. Available: http://www.azom.com/article.aspx?ArticleID=8353 \#3, [Accessed: Nov.10, 2016].

[3] S. K. Mazumdar, Composites manufacturing : materials, product, and process engineering,USA: CRC Press, 2001.

[4] I. Petrescu, C. Mohora, and C. Ispas, "The Determination of Young Modulus For CFRP Using Three Point Bending Test at Different Span Lengths," Journal Scientific Bulletin Series D, 75(1), pp. 121-128, 2013.

[5] A. Azzam and W. Li, "An experimental investigation on the three-point bending behavior of composite laminate," in IOP Conference Series: Materials Science and Engineering, pp.12-16, 2014.

[6] O. Elalaoui, E. Ghorbel, V. Mignot, and M. Ben Ouezdou, "Mechanical and physical properties of epoxy polymer concrete after exposure to temperatures up to $250^{\circ} \mathrm{C}$," Construction and Building Materials, 27(1), pp. 415-424, 2012.

[7] J. Nunes, A. Pouzada, and C. Bernardo, "The use of a three-point support flexural test to predict the stiffness of anisotropic composite plates in bending," Polymer testing, 21(1), pp. 27-33, 2002.

[8] J. M. L. d. Reis, "Effect of textile waste on the mechanical properties of polymer concrete," Materials Research, 12(1), pp. 63-67, 2009.

[9] I. A. Subagia, Y. Kim, L. D. Tijing, C. S. Kim, and H. K. Shon, "Effect of stacking sequence on the flexural properties of hybrid composites reinforced with carbon and basalt fibers," Composites Part B: Engineering, 58, pp. 251-258, 2014.

[10] A. Ongun, A. Avci, S. Picak, and A. Erisen, "Three Point Bending Test Research of Carbon Fibre Composites Incorporating Nanoclay," presented at the Proceedings of The IRES 21st International Conference, 25th December 2015, Amsterdam, Netherland, pp.80-82, 2015.

[11] Y. I. Dimitrienko, "Thermomechanical behaviour of composite materials and structures under high temperatures: 1. Materials," Composites Part A: Applied Science and Manufacturing, 28(5), pp. 453-461, 1997.

[12] P. Ciobanu, N. Taranu, S. Popoaei, and D. Banu, "Structural Response of Reinforced Concrete Beams Strengthened in Flexure with near Surface Mounted Fibre Reinforced Polymer Reinforcement Experimental Setup," Journal of Polytechnic Institute of Lasi, 58(4), pp. 109-118, 2012. 
[13] H. Shehab EI-Din and H. A. Mohamed, "Effect of temperature on strength of concrete strengthening with CFRP," International Journal of Engineering Science and Innovating Technology, 2(5), 2012.

[14] S. Al-Sheikh and A. Abdallah, "Effect of Elevated Temperature on Flexural Behavior of RC Beams with NSM CFRP," Journal of Civil \& Environmental Engineering, 7(1), pp.110-117 2017.

[15] J. Gamage, M. Wong, and R. Al-Mahaidi, "Bond performance of CFRP plated concrete members at elevated temperatures," Australian Structural Engineering Conference, Australia, pp. 934-938, 2005.

[16] J. Reis, "Effect of temperature on the mechanical properties of polymer mortars," Materials Research, 159(4), pp. 645-649, 2012.

[17] A. Di Tommaso, U. Neubauer, A. Pantuso, and F. Rostasy, "Behavior of adhesively bonded concreteCFRP joints at low and high temperatures," Mechanics of Composite Materials, 37(4), pp. 327338, 2001

[18] E. L. Klamer, D. A. Hordijk, and H. J. Janssen, "The influence of temperature on the debonding of externally bonded CFRP," Special issue of ACI, 23(0), pp. 1551-70, 2005.

[19] L. Resin \& Designs, "The Importance of Epoxy Glass Transition Temperature," 2016. [Online]. Available: http://resindesigns.com/2016/05/10/theimportance-of-epoxy-glass-transitiontemperature/\#top. [Accessed: Sept. 12,2016]

[20] Sigmatex, "Global Carbon Composite Solutions," in "Material Innovation," Sigmatex UK Limited, UK2014. [Online]. Available: http://www.sigmatex.com/technical/technicalspecifications/, [Accessed: June 17, 2017.

[21] Sicomin-Composites, "Epoxy resin systems Multi purpose for composites applications," 2013. [Online]. Available: http://www.matrixcomposites.co.uk/prod-data-sheet/old/sr-8500860x-uk.pdf, [Accessed Feb. 06, 2017].

[22] ISO 14125, "Fibre-reinforced plastic compositesdetermination of flexural properties," European Committee for Standardization1998, [Online].
Available:

http://www.iso.org/iso/catalogue_detail.htm?csnum ber $=23637$, [Accessed: May, 05, 2015.

[23] AST D790-07, "Standard Test Methods for Flextural Properties of Unreinforced and Reinforced Plastics and Electrical Insulating Materials," 8 (1), 2007.

\section{ACKNOWLEDGEMENTS}

The author would like to acknowledge the support that both the Polytechnic University of Slemani and the University of Plymouth have given to complete this work. Also the author would like to thank Barzan Akram Mohammed (Sulaimani Polytechnic University) who assisted with some aspects of the experimental work.

\section{BIOGRAPHY}

Dr. Rzgar Mhammed Abdalrahman is a member of teaching staff at the production engineering and metallurgy department of technical college of engineering at Sulaimani Polytechnic University. He started as an assistant lecturer in 1990 then promoted to lecturer in 2010.

He awarded B.Sc. degree in production engineering in 1981-1985 and M.Sc. degree with a thesis entitled (Behavior of Cutting Tool in Threading) in 1988 at production engineering and metallurgy department of University of Technology / Baghdad-Iraq. Also awarded Diploma of Membership of Plymouth University in 2015-2016 and PhD in recognition of a programme of work entitled (Design and Analysis of Integrally-Heated Tooling for Polymer Composites) in 2015-2016 at faculty of science and engineering / School of marine science and engineering of Plymouth University / UK.

He published six articles in the journals of; Zankoy Sulaimani in 2010, Pure and Applied Sciences / Salahaddin University in 2010, Materials and design in 2014, Reinforced plastics and composites in 2016 as well as in 2017 and an article at the proceeding of ECCM16 conference in 2014. 